\title{
Study of Hepatoprotective Activity of Saussurea Lappa Root Extract
}

\author{
Juluri Krishna Dutta Tejaswi, Dr. R. Govinda Rajan, P. Sara \\ Department of Pharmaceutical Chemistry, Hindu College of Pharmacy, \\ Guntur, Andhra Pradesh, India
}

\begin{abstract}
The plant under evaluation was Saussure a lappa, a plant of Asteraceae, one of the best-known species within this genus, was commonly known as costus in English. Based on the literature survey, it was reported that various pharmacological activities were reported on Saussure a lappa. After authentification, the collected plant root material it was reduced into small pieces. The plant material was extracted by using ethanol by the cold maceration method. The study concluded that the root extract have potential bioactive substances that may be used to formulate new drugs. The Flavo-Glycosides content in Ethonolic extract of Saussure a lappa root extract for Hepatoprotective activity was evaluated. The results were compared with the standard using statistical method. However further investigation was required for structural elucidation and pharmacological properties.
\end{abstract}

KEYWORD: Saussure a lappa, Asteraceae, Ethonolic, Glycosides, Hepatoprotective

\section{INTRODUCTION}

Liver is one of the largest organs in human body and the chief site for intense metabolism and excretion. So it has a surprising role in the maintenance, performance and regulating homeostasis of the body. Thus liver diseases are some of the fatal disease in the world today. Modern medicines have little to offer for alleviation of hepatic diseases and it is chiefly the plant based preparations which are employed for their treatment of liver disorders.

Saussure a lappa [1-4] is found at an altitude of 2,500 to $3,000 \mathrm{~m}$ in Kashmir and neighboring Himalayan regions. In view of this, the present study was aimed to carryout biological evaluation of the obtained Flavo-Glycosides content in Ethonolic extract of Saussurea lappa root extract for Hepatoprotective activity is determined. From the literature review [59] plant was reported to be rich in Costunolide, Sitosterol, $\alpha$ and $\beta$-Cyclocostunolide, Guiainolides, Cynaropicrin, Reynosin, Saussurealdehyde, Isodehydrocostus-Lactone-15-Aldehyde, 11,13Epoxy-IsozazulaninC, Lignin Glycoside, Sesquiterpenes, Guiainolides, Lappalone and 1, 6Dihydroxycostic acid ethyl ester.

\section{MATERIALS AND METHOD [10-13] \\ Preparation of Plant Extract}

The aerial plants of Saussurea lappa (Asteracae) a branched herb were collected from the Tirupathi region, A.P. India. The collected plant root material were washed with tap water to removing adhering dust followed by distilled water, shade dried, and size reduced into small pieces and stored in polythene bags for use. The extractive values were also found to be within the limits. The Ethonolic extract was taken for the fraction of compound using chloroform and methanol by Solvent-Solvent separation method and the $\%$ yield was calculated 1.5 and $1.7 \%$ respectively.

\section{Animals}

Albino rats (Wistar strain) of either sex weighing between 250-300 $\mathrm{g}$ and Albino mice of either sex weighting 20-30g were acclimatized for seven days under laboratory conditions. The animals were fed with commercially available rat pellet diet.

\section{Determination of Acute Toxicity (LD50)}

Ethonolic extract of Saussure a lappa root was suspended in water, to prepare a dose of $4000 \mathrm{mg} / \mathrm{kg}$ body weight of animal, and administered 1ml/100gm body weight of the animal. The procedure was divided into two phases, Phase I (observation made on day one), and Phase II (observed the animals since next 14 days). Two set of healthy female rats (each set of 3 rats) were used for the experiment. First set 
animals were divided and fasted for 18 hours deprived from food, water withdrawn before 4 hours of the dosing, body weights were noted before and after dosing with Ethanolic extract of Saussure a lappa $(4000 \mathrm{mg} / \mathrm{kg})$ orally. Individually animals were observed for 4 hours to see any clinical symptoms, any change in behaviour or mortality. 6 hours post dosing again body weights recorded. Form the next day onwards, each day for 1 hour the behavioural change, clinical symptoms or mortality was observed in the same animals for next 14 days and animal body weights were recorded on 8th and 14th day. The same procedure was repeated to nullify the errors.

\section{$\mathbf{C C l}_{4}$ Induced Hepatoprotective Activity}

Liver injury due to carbon tetrachloride in rats was first reported in 1936 -39. Administration of a single dose of $\mathrm{CCl}_{4}$ to a rat produces, within $24 \mathrm{hrs}$, a centrilobular necrosis and fatty changes. The poison reaches its maximum concentration in the liver within $3 \mathrm{hrs}$ of administration. Thereafter, the level falls and by $24 \mathrm{hrs}$ there is no $\mathrm{CCl}_{4}$ left in the liver. The development of necrosis is associated with leakage of hepatic enzymes into serum. Dose of $\mathrm{CCl}_{4}$ : 0.1 to 3 $\mathrm{ml} / \mathrm{kg}$ I.P. The experimental Wister stain albino rats of age between 50-60days weighing between 180-250gm were divided into 5 groups of 6 animals each as shown in Table 1.

Table 1: Group and Dose in $\mathrm{CCl}_{4}$ Induced Hepatoprotective Activity.

\begin{tabular}{|c|l|}
\hline Group & \multicolumn{1}{|c|}{ Dose } \\
\hline A & Normal (1ml/kg, per oral.) \\
\hline B & Negative Control- $\mathrm{CCl}_{4}(1.25 \mathrm{ml} / \mathrm{kg}$ i.p. $)$ \\
\hline C & Standard Drug - Silymarin $(100 \mathrm{mg} / \mathrm{kg})$ \\
\hline D & Dose of SLEE $(250 \mathrm{mg} / \mathrm{kg})$ \\
\hline E & Dose of SLEE $(500 \mathrm{mg} / \mathrm{kg})$ \\
\hline
\end{tabular}

\section{RESULTS AND DISCUSSION \\ Histopathological Studies}

The animals were sacrificed and the liver of each animal was isolated and was cut into small pieces, preserved and fixed in $10 \%$ formalin for two days. Then the liver piece was washed in running water for about 12 hours to remove the formalin and was followed by dehydration with isopropyl alcohol of increasing strength $(70 \%, 80 \%$ and $90 \%)$ for 12 hours each. Then finally dehydration is done using absolute alcohol with about three changes for 12 hours each. Dehydration was performed to remove all traces of water. Further alcohol was removed by using chloroform and chloroform removed by paraffin infiltration. The clearing was done by using chloroform with two changes for 15 to 20 minutes each. After paraffin infiltration the liver pieces were subjected to automatic tissue processing unit. Hard paraffin was melted and the hot paraffin was poured into L-shaped blocks.

The liver pieces were then dropped into the molten paraffin quickly and allow cooling. The blocks were cut using microtome to get sections of thickness of 5 . The sections were taken on a micro slide on which egg albumin i.e., sticking substance was applied. The sections were allowed to remain in an oven at $600^{\circ} \mathrm{C}$ for 1 hour. Paraffin melts and egg albumin denatures, thereby fixing tissue to slide. Eosin is an acid stain; hence it stains all the cell constituents pink which are basic in nature.

\section{Wet Liver Weight and Wet Liver Volume}

Animals were sacrificed and livers were isolated and washed with saline and weight its body weight i.e. $\mathrm{gm} / 100 \mathrm{gm}$. On the last day, Thiopentone sodium (40 $\mathrm{mg} / \mathrm{kg}$, i.p) was injected and the sleeping time recorded in all the animals. The biochemical parameters were estimated as per the standard procedure prescribed by the manufacturer's instruction manual provided in the kit. (Coral clinical systems, Verna Goa, India) using Semi Auto analyser (ARTOS) by $\mathrm{CCl}_{4}$ (1.25ml/kg i.p.) . When with control was shown significant activity $(\mathrm{P}<0.001)$, and compared with standard was shown to equal activity at concentration of SLEE $500 \mathrm{mg} / \mathrm{kg}$ body weight. The activity was shown the dose dependent. The results are shown in Table 2, Fig.1 and Fig.2.

Table 2: Effect of $\mathbf{C C l}_{4}$ Induced Hepatotoxic Rats.

\begin{tabular}{|c|c|c|}
\hline Group & $\begin{array}{c}\text { Wet liver } \\
\text { Weight(gm/100gm) }\end{array}$ & $\begin{array}{c}\text { wet liver } \\
\text { volume(gm/100gm) }\end{array}$ \\
\hline $\mathrm{A}$ & $2.90 \pm 0.49$ & $2.83 \pm .41$ \\
\hline $\mathrm{B}$ & $5.01 \pm 0.12^{\$ \$}$ & $4.78 \pm 0.11^{\$ \$ \$}$ \\
\hline $\mathrm{C}$ & $2.33 \pm 043^{* * *}$ & $2.50 \pm 0.29^{* * *}$ \\
\hline $\mathrm{D}$ & $2.59 \pm 0.45^{* * *}$ & $2.47 \pm 0.37^{\text {*** }}$ \\
\hline $\mathrm{E}$ & $2.29 \pm 0.33^{* * *}$ & $2.21 \pm 0.25^{\text {*** }}$ \\
\hline
\end{tabular}

$\$ \$ \$-\mathrm{P}<0.001$ - Disease control compared with normal control group, $* * *_{-} \quad \mathrm{P}<0.001$ - Individual readings were compared with readings of disease control using One way ANOVA followed by Tukey test. $(n=6)$. 
Wet liver weight

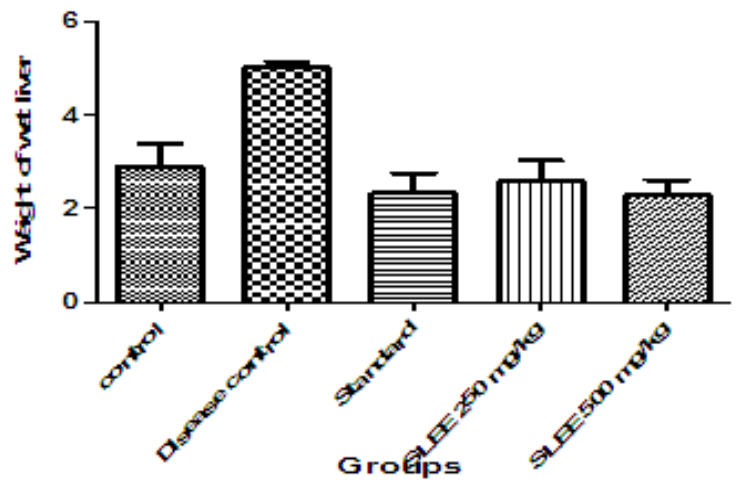

Fig.1: Effect on Wet Liver Weights
Liver volume

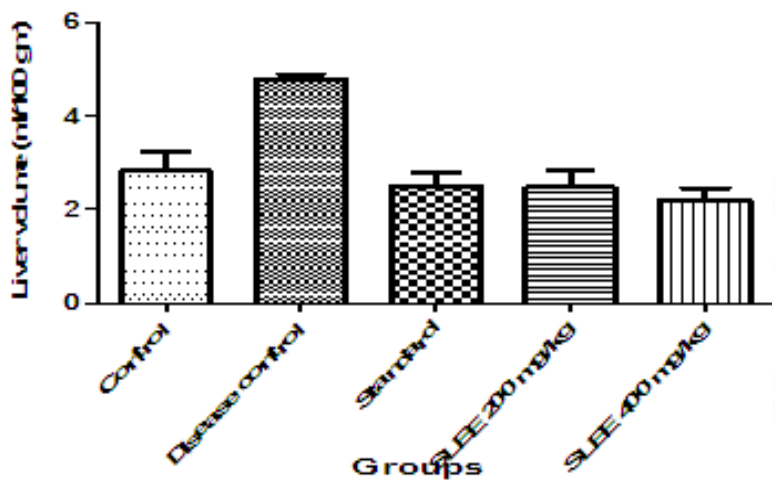

Fig.2: Effect on Wet Liver Volume

\section{SGPT, SGOT and ALP Levels}

Rats treated with ethanol developed a significant hepatic damage observed as elevated serum levels of hepatospecific enzymes like SGPT, SGOT and SALP when compared to normal control by $\mathrm{CCl}_{4}(1.25 \mathrm{ml} / \mathrm{kg}$ i.p.). Pre-treatment with Silymarin, methanolic extract had showed good protection against ethanol induced toxicity to liver. When with control was shown significant activity $(P<0.001)$, and compared with standard was shown to equal activity at concentration of SLEE $500 \mathrm{mg} / \mathrm{kg}$ body weight. Test indicates a significant reduction in elevated serum enzyme levels with extract treated animals compared to disease control animals which are evident in Table 3, Fig.3, Fig.4 and Fig.5.

Table 3: Effect on SGPT, SGOT \& SALP Levels in $\mathrm{CCl}_{4}$ Induced Hepatotoxic Rats.

\begin{tabular}{|c|c|c|c|c|c|c|}
\hline \multirow{2}{*}{ Group } & \multicolumn{2}{|c|}{ SGPT(U/L) } & \multicolumn{2}{c|}{ SGOT(U/L) } & \multicolumn{2}{c|}{ ALP(U/L) } \\
\cline { 2 - 7 } & $0^{\text {th }}$ day & $7^{\text {th }}$ day & $0^{\text {th }}$ day & $7^{\text {th }}$ day & $0^{\text {th }}$ day & $7^{\text {th }}$ day \\
\hline A & $28.31 \pm 1.17$ & $30.35 \pm 0.90$ & $28.96 \pm 1.56$ & $32.14 \pm 2.12$ & $28.02 \pm 1.74$ & $29.15 \pm 1.14$ \\
\hline B & $28.37 \pm 1.75$ & $90.91 \pm 1.50^{\$ \$ \$}$ & $28.74 \pm 1.89$ & $81.95 \pm 1.35^{\$ \$ \$}$ & $27.90 \pm 1.59$ & $69.24 \pm 1.38^{\$ \$ \$}$ \\
\hline C & $27.99 \pm 0.85$ & $35.57 \pm 0.15^{* * *}$ & $27.90 \pm 0.98$ & $38.86 \pm 0.70^{* * *}$ & $28.73 \pm 0.54$ & $33.81 \pm 0.19^{* * *}$ \\
\hline D & $27.92 \pm 1.04$ & $38.64 \pm 0.55^{* * *}$ & $28.45 \pm 0.56$ & $42.56 \pm 0.75^{* * *}$ & $27.84 \pm 1.81$ & $40.94 \pm 2.05^{* * *}$ \\
\hline E & $28.58 \pm 0.94$ & $32.54 \pm 0.05^{* * *}$ & $29.67 \pm 0.77$ & $38.31 \pm 0.50^{* * *}$ & $27.91 \pm 1.37$ & $35.60 \pm 0.97^{* * *}$ \\
\hline
\end{tabular}

$\$ \$ \$$-P $<0.001$ - Disease control compared with normal control group, $* * *-\mathrm{P}<0.001$ - Individual readings were compared with readings of disease control using One way ANOVA followed by Tukey test. $(n=6)$.

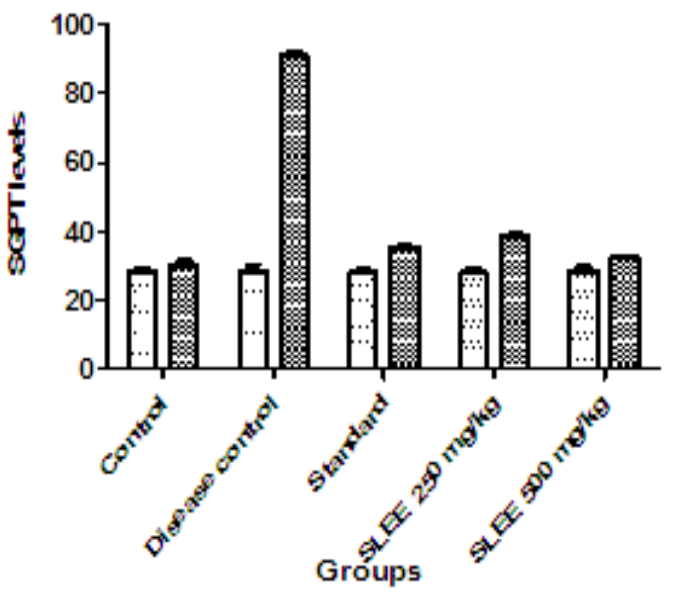

Fig.3: Effect on SGPT levels

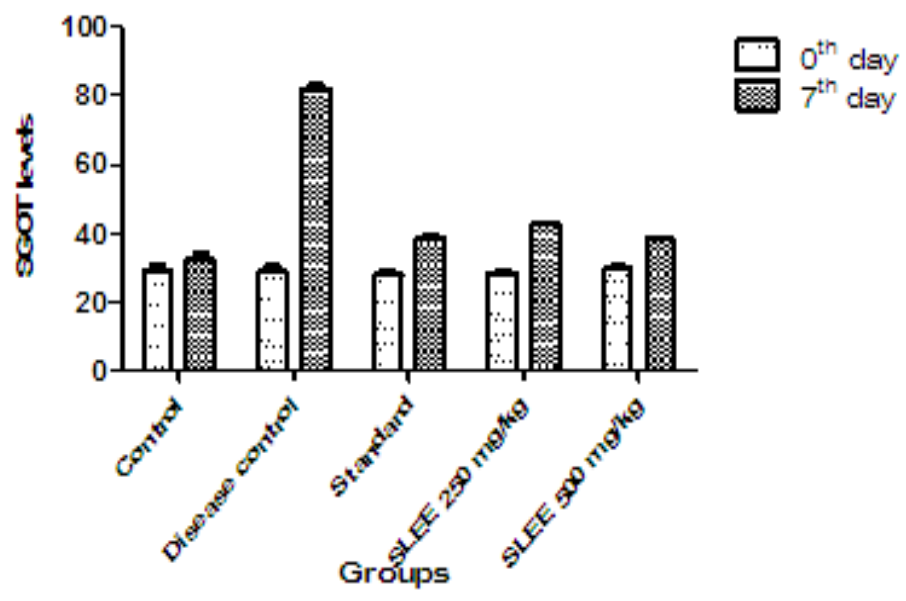

Fig.4: Effect on SGOT Levels 


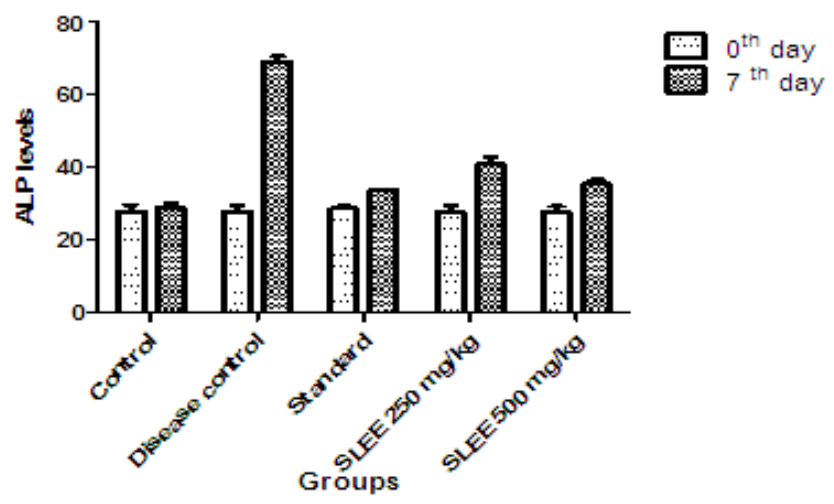

Fig.5: Effect on ALP Level

\section{Direct Bilirubin and Total Bilirubin}

Elevation of direct and total Bilirubin levels after administration of $\mathrm{CCl}_{4}(1.25 \mathrm{ml} / \mathrm{kg}$ i.p.) indicates its hepatotoxicity. When with control was shown significant activity $(P<0.001)$, and compared with standard was shown to equal activity at concentration of SLEE $500 \mathrm{mg} / \mathrm{kg}$ body weight. Pre-treatment with Silymarin, Methanolic extract significantly reduced levels of direct and total Bilirubin levels when compared to toxic control group indri citing Hepatoprotective effect of Ethonolic extract of Saussure a lappa root which can be seen in Table 4, Fig.6 and Fig.7.

Table 4: Effect on Direct Bilirubin \& Total Bilirubin in $\mathbf{C C l}_{4}$ induced hepatotoxic rats.

\begin{tabular}{|c|c|c|c|c|}
\hline \multirow{2}{*}{ Group } & \multicolumn{2}{|c|}{ Direct Bilirubin(mg/dl) } & \multicolumn{2}{c|}{ Total Bilirubin(mg/dl) } \\
\cline { 2 - 5 } & $\mathbf{0}^{\text {th }}$ day & $7^{\text {th }}$ day & $0^{\text {th }}$ day & $7^{\text {th }}$ day \\
\hline A & $0.17 \pm 0.04$ & $0.19 \pm 0.12$ & $0.19 \pm 0.05$ & $0.21 \pm 0.01$ \\
\hline B & $0.17 \pm 0.03$ & $0.78 \pm 0.13^{\$ \$}$ & $0.19 \pm 0.04$ & $0.99 \pm 0.14^{\$ \$}$ \\
\hline C & $0.18 \pm 0.02$ & $0.34 \pm 0.01^{* * *}$ & $0.20 \pm 0.06$ & $0.45 \pm 0.05^{* * *}$ \\
\hline D & $0.16 \pm 0.06$ & $0.41 \pm 0.02^{* * *}$ & $0.18 \pm 0.02$ & $0.50 \pm 0.07^{* * *}$ \\
\hline E & $0.17 \pm 0.06$ & $0.36 \pm 0.19^{* * *}$ & $0.19 \pm 0.07$ & $0.45 \pm 0.03^{* * *}$ \\
\hline
\end{tabular}

$\$ \$ \$-\mathrm{P}<0.001$ - Disease control compared with normal control group, $* * *-\mathrm{P}<0.001$ - Individual readings were compared with readings of disease control using One way ANOVA followed by Tukey test. $(n=6)$.

Direct Bilirubin levels

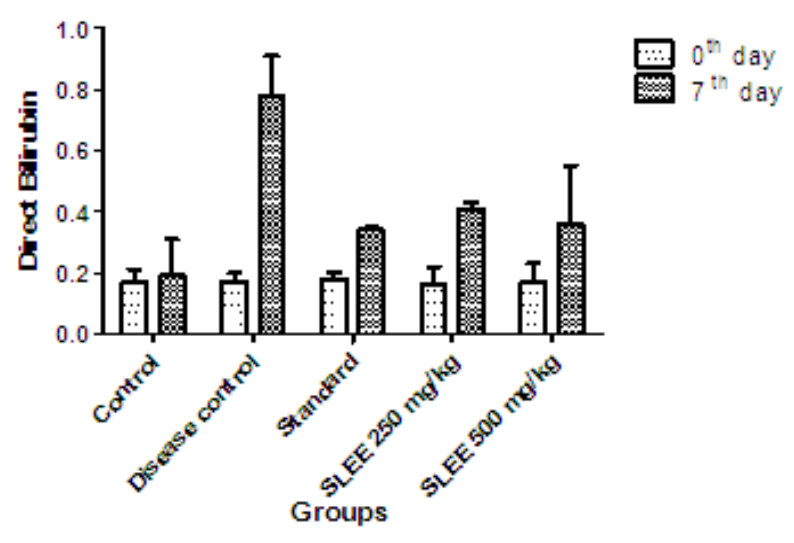

Fig.6: Effect on Direct Bilirubin Levels
Total BIIIrubln levels

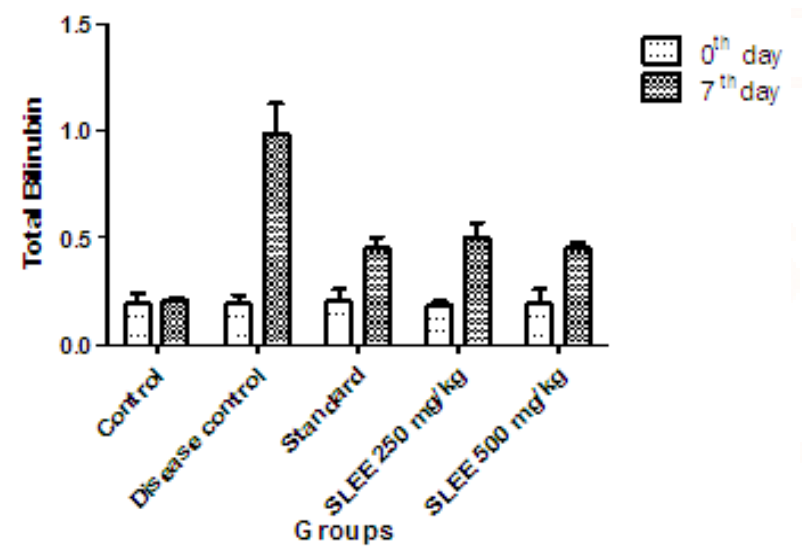

Fig.7: Effect on Total Bilirubin Levels

\section{Serum Total Protein Levels and Cholesterol}

$\mathrm{CCl}_{4}$ treatment has considerably reduced serum total protein levels. Pre-treatment with Silymarin and Ethanolic extract of Saussure a lappa root had showed a significant increase in total protein levels as compared with toxicant group. From the results it was found that rats treated with $\mathrm{CCl}_{4}(1.25 \mathrm{ml} / \mathrm{kg}$ i.p.) showed a marked increase in cholesterol levels when compared to normal control group. When with control was shown significant activity $(P<0.001)$, and compared with standard was shown to equal activity at concentration of SLEE $500 \mathrm{mg} / \mathrm{kg}$ body weight. The activity was shown the dose dependent. The rats pre-treated with Silymarin and Ethanolic extract of Saussure a lappa root the serum cholesterol levels had significantly decreased when compared to toxicant group as shown in Table 5, Fig.8 and Fig.9. 
International Journal of Trend in Scientific Research and Development (IJTSRD) ISSN: 2456-6470

Table 5: Effect on serum Total protein \& cholesterol in $\mathbf{C C l}_{4}$ induced hepatotoxic rats. Group $\quad$ Total protein levels (gm/dl ) Serum cholesterol levels (gm/dl )

\begin{tabular}{|c|c|c|c|c|}
\hline $\mathrm{A}$ & $5.33 \pm 0.67$ & $6.93 \pm 0.16$ & $45.76 \pm 1.86$ & $45.14 \pm 1.97$ \\
\hline $\mathrm{B}$ & $5.67 \pm 0.99$ & $3.92 \pm 0.38^{\$ \$ \$}$ & $44.89 \pm 1.93$ & $110.16 \pm 1.12^{\$ \$ \$}$ \\
\hline $\mathrm{C}$ & $5.83 \pm 0.87$ & $5.77 \pm 0.42^{\text {*** }}$ & $45.15 \pm 1.74$ & $60.83 \pm 1.90^{\text {*** }}$ \\
\hline $\mathrm{D}$ & $5.74 \pm 0.93$ & $5.97 \pm 0.56^{\text {*** }}$ & $43.87 \pm 1.38$ & $73.66 \pm 2.89^{\text {*** }}$ \\
\hline $\mathrm{E}$ & $5.55 \pm 0.76$ & $6.49 \pm 0.64^{* * *}$ & $43.31 \pm 1.66$ & $65.21 \pm 1.97^{\text {*** }}$
\end{tabular}

$\$ \$ \$$-P $<0.001$ - Disease control compared with normal control group, $* * *$ - $\mathrm{P}<0.001$ - Individual readings were compared with readings of disease control using One way ANOVA followed by Tukey test.
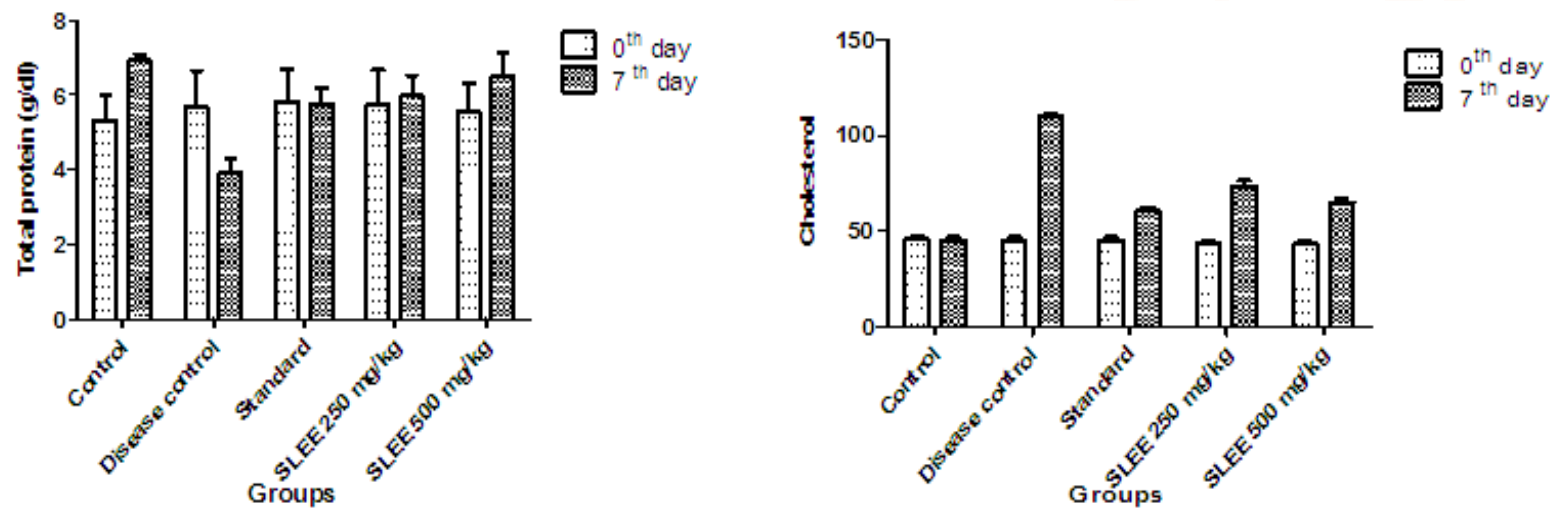

Fig.8: Effect on Total Protein Levels Fig.9: Effect on Serum Total Cholesterol Levels

\section{CONCLUSION}

The Saussure a lappa root was extracted, separated and isolated. The Ethonolic extract was first prepared and was screened for various phytochemical constituents. From this Ethonolic extract Ethyl acetate fraction was obtained using Solvent- Solvent separation technique. The fraction was screened for spectral studies of phyto-constituents. The Ethyl acetate fraction of the methanol extract was found to contain Flavonoids and Glycosides. Furthermore evaluation was done for the Hepatoprotective activity of the Saussure a lappa root extract which showed the better activity by doing the $\mathrm{CCl}_{4}$ induced hepatotoxic experiment. The increased serum triglyceride level in ethanol-treated rats may be due to the decreased activity of lipoprotein lipase, which is involved in the uptake of triglyceride-rich lipoprotein by the extra hepatic tissues. Pre-treatment with Ethonolic extract of root of Saussure a lappa reduced the elevated cholesterol and triglyceride levels, suggesting that the extracts prevented ethanol-induced hyperlipidemia probably due to their Hepatoprotective activity. Reduced levels of cholesterol and triglycerides in ethanol induced hepatotoxic animals, indicating the hepatoprotection.

\section{ACKNOWLEDGEMENT}

Authors are thankful to Hindu College of Pharmacy, Amaravathi Road, Guntur, Andhra Pradesh, India to provide the infrastructures to pursue the work.

\section{REFERENCES}

1. Bose. Some aspects of phytochemical and pharmacological study of Saussure a Lapp a. J of Pharm Sci, 1961, 50: 679-681.

2. Uma Chandur. Phytochemical Evaluation and Anti-Arthritic Activity of Root of Saussure a Lapp a. Pharmacologia, 2011, 2: 265-267.

3. Thara K. M. Comprehensive In-vitro pharmacological activities of different extracts of Saussure a Lapp a. J of Experimental Bio, 2012; 2 (2):417-420.

4. Mohammad Asim Khan. Qust (Saussure a Lapp a Clarke.) - A Potent Herb of Unani Medicine: A Review. Int J of Cur Pharm Res, 2013; 5 (4): 163170.

5. Ravi Shankar Pandey. Saussure a Lapp a extract modulates cell mediated and hum oral immune response in mice. Der Pharmacia Lettre, 2012; 4 (6): 1868-1873. 
6. Gupta Push p raj. Anticonvulsant Activity of Saussure a Lapp a. Pharmacology, 2009; 3: 809814.

7. Negi1.J.S. Ant diarrheal activity of methanol extract and major essential oil contents of Saussure a Lapp a Clarke. Afr J of Pharmacy and Pharm, 2013; 7(8): 474-477.

8. Anbu. J. Evaluation of antihyperlipidemic Activity of Ethanolic Extract of Saussure a Lapp a in Rats. Int J of Pharma and Bio Sci, 2011; 2: 168175.

9. Niranjan Sutar. Antiulcerogenic Activity of Saussure a Lapp a Root. Int J of Pharm \& Life Sciences, 2011, 2(1): 87-95.
10. Madhusudana Rao. A new Sesquiterpenes Lactone from the roots of Saussure a Lapp a Structureanticancer activity study. Bioorganic \& Med Chem., 2008, 18: 4015-4017.

11. Cho. Inhibitory effect of Sesquiterpenes lactones from Saussure a Lapp a on tumor necrosis factoralpha production in murine macrophage like cells. Plant a Medica, 1998, 64: 594-597.

12. Chen. Effect of Saussure a Lapp a on gastric functions. Plant a Medica, 1994, 14: 406-408.

13. Chen. Active compounds from Saussure a Lapp a Clarke that suppress hepatitis B virus surface antigen gene expression in human hepatoma cells. Antiviral Res, 1995, 27: 99-109. 